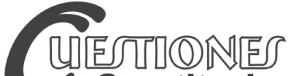

\section{SISTEMA PARLAMENTARIO Y RÉGIMEN ELECTORAL EN ESPAÑA: SIMILITUDES Y DIFERENCIAS ENTRE LA FORMA DE GOBIERNO EN EL ESTADO Y LAS COMUNIDADES AUTÓNOMAS}

\author{
PARLIAMENTARY SYSTEM AND ELECTORAL SYSTEM \\ IN SPAIN: SIMILITUDES AND DIFERENCES \\ AMONG STATE AND AUTONOMOUS COMMUNITIES ` \\ GOVERNMENT
}

\begin{abstract}
RESUMEN: Este artículo revisa las principales características del sistema parlamentario español -que potencia los elementos presidencialistasy su relación con el sistema electoral — de tipo proporcional con efectos mayoritarios-. Ambos se han mantenido prácticamente sin cambios desde la transición política a la democracia y a lo largo de los más de treinta años de régimen constitucional. Los efectos que han provocado han sido el monopolio absoluto de los partidos en la vida pública, una gran estabilidad política, pero también un alejamiento progresivo de los ciudadanos de las instituciones representativas. Los mismos rasgos se extienden de forma semejante a la forma de gobierno y régimen electoral de las comunidades autónomas. No obstante, las reformas de los estatutos de autonomía de las comunidades autónomas de la última década han introducido de forma tímida algunas figuras novedosas.
\end{abstract}

Palabras clave: forma de gobierno; sistema parlamentario racionalizado; sistema proporcional; Estado autonómico español.

\section{Josep-Maria CASTELLÁ ANDREU*}

ABSTRACT: This article deals with the main characteristics of the Spanish parliamentary system — which underlines presidential supremacy - and its relationship with the electoral system - proportional with majoritarian results - Both elements have remained unchangeable since the transition to the democracy and during more than thirty years of constitutional regime. The effects produced are the monopoly of the political parties in the public life and a great political stability, but at the same time a progressive distance between citizens and representative institutions. The same features extend similarly to the government and electoral system of the autonomous communities. However Statutes' amendments of the last decade have introduced timidly some new rules.

Descriptors: government; parliamentary and rationalised system; proportional system; Spanish decentralization.

* Profesor titular de Derecho Constitucional de la Universidad de Barcelona y catedrático por la ANECA. 


\section{INTRODUCCIÓN}

En España, por lo general, los constitucionalistas han prestado poca atención a la forma de gobierno y su relación con el sistema electoral. Asimismo, escasa ha sido la innovación normativa en esos dos campos, tomados por separado, desde la aprobación de la Constitución de 1978 y las normas que la desarrollaron (incluso desde antes: desde la Ley para la Reforma Política de 1977 y los decretos ley de desarrollo, en plena transición política a la democracia). Apenas se ha producido "ingeniería constitucional", ni en el plano general del Estado ni tampoco en el de las comunidades autónomas (CCAA). La estabilidad normativa y la parquedad de propuestas políticas y también académicas han predominado a lo largo de los ya más de treinta años de vida democrática constitucional. Dichas estabilidad y parquedad se han extendido a las CCAA, cuyos estatutos de autonomía, en lo sustancial, han seguido el mismo modelo normativo que el Estado.

No obstante, ha sido en el ámbito autonómico o subnacional donde se han producido algunas novedades tanto de orden normativo como político de cierto relieve que han dado lugar a experiencias prácticas diferentes a las del Estado. Si en el plano estatal las reformas normativas han quedado, por ahora, en meras propuestas a debatir (sobre todo de reforma electoral), en las CCAA las últimas reformas de los estatutos, a partir de 2006, han significado ciertos cambios notables, que han acentuado los rasgos similares entre la forma de gobierno de todas las CCAA a partir de las no desdeñables diferencias iniciales, al tiempo que remarcaban las diferencias con la forma de gobierno estatal.

Ahora, en el momento de la grave crisis económico-financiera que vive España, aflora también otra crisis político-institucional que tiene que ver con la percepción de un cada vez mayor alejamiento entre ciudadanía e instituciones representativas. Esta última crisis de confianza política y de legitimación democrática pone sobre el tapete la crítica a la regulación y al funcionamiento de los partidos y las instituciones de gobierno al tiempo que hace emerger propuestas de reforma del sistema político, en particular del régimen electoral y de los instrumentos de participación ciudadana.

A continuación, repasaremos los rasgos básicos del sistema, que emergen de la Constitución de 1978, de la legislación de desarrollo y de la dinámica política (apartado 2), y su traslación matizada a las CCAA - y munici- 
pios- desde el punto de vista normativo aunque los efectos políticos de su aplicación práctica hayan producido diferencias notables respecto a lo ocurrido en el plano general del Estado (apartado 3).

\section{CARACTERÍSTICAS BÁSICAS DEL SISTEMA: UN MARCO JURÍDICO ESTABLE}

\section{Situación legal vigente y efectos en la realidad}

La Constitución de 1978 contiene las opciones político-jurídicas fundamentales sobre la forma de gobierno, el sistema electoral y el régimen de partidos. España se configura como una monarquía parlamentaria racionalizada al tiempo que se constitucionaliza la proporcionalidad del sistema electoral en todas las instituciones representativas de todos los niveles de gobierno, excepto el Senado. Ambas opciones constitucionales en relación con la forma de gobierno y el sistema electoral se han de poner en un contexto más amplio, el de la forma de Estado. En España, el Estado democrático se concreta, desde la Constitución misma, en una democracia representativa, que apenas deja un espacio mínimo a las instituciones de democracia directa y semidirecta, las cuales, en todo caso, no condicionan la concreta forma de Estado ni la de gobierno. ${ }^{1}$ En efecto, el referéndum por el que opta la norma suprema, con carácter general, es el consultivo sobre decisiones relevantes de especial trascendencia, a iniciativa del presidente del gobierno y necesaria autorización del Congreso de los Diputados (artículo 92 de la CE), a parte de los referendos de reforma constitucional (artículos 167 y 168 de la CE) y de aprobación y reforma de los Estatutos de las CCAA llamadas de vía rápida o de régimen especial. ${ }^{2}$ Asimismo, la previsión de la iniciativa legislativa

1 Aguiar de Luque, Luis, "Democracia directa e instituciones de democracia directa en el ordenamiento constitucional español", en Trujillo, Gumersindo, López Guerra, Luis y González Trevijano, Pedro (dirs.), La experiencia constitucional (1978-2000), Madrid, CEPC, 2000, pp. 76 y ss.

2 País Vasco, Cataluña, Galicia y Andalucía. Ello es así de acuerdo con lo dispuesto en el artículo 152.2 CE, que a partir de 2006 ha sido extendido en los respectivos Estatutos, en el caso de reforma estatutaria, a la Comunidad Valenciana, Aragón y Extremadura, en virtud de la habilitación para regular el procedimiento de reforma que tienen ex artículo 147.3 de la CE. 
popular se ve rodeada de todo tipo de cautelas y de una gran rigidez para su realización (artículo 87.3 de la CE y LO 4/1984 modificada en 2006). ${ }^{3}$

Así pues, la democracia española es una democracia parlamentaria, en que las instituciones representativas prácticamente tienen el monopolio en el ejercicio del principio democrático. Ello conlleva una valoración particular del papel de los partidos políticos (artículo 6 de la CE, en el Título preliminar). Esta opción del constituyente no ha dejado de acentuarse por vía legislativa, jurisprudencial y en la práctica política hasta el día de hoy. La opción del constituyente por la democracia representativa se basó en la necesidad de fortalecer a los partidos, tan débiles tras cuarenta años de régimen autoritario y de partido único. Se trataba, sin duda, de una justificación atendible en aquel contexto de los años de la Transición a la democracia. Sin embargo, su inserción en la Norma Fundamental ha convertido el predomino de la democracia de partidos y, en general, de la democracia sólo representativa, en un factor estructural, con vocación de permanencia, del sistema constitucional español.

La norma fundamental se refiere a la Monarquía parlamentaria como "la forma política del Estado" (artículo 1.3. de la CE), lo que para buena parte de la doctrina constitucionalista significa que la forma de gobierno que se constitucionaliza es el sistema parlamentario con el Rey como Jefe del Estado. Si en otras monarquías occidentales el paso de la monarquía constitucional a la parlamentaria se ha producido por vía de convenciones y costumbres constitucionales, en España, la Constitución al definir la Monarquía restaurada tras la muerte de Franco lo hace expresamente como "parlamentaria". El monarca ostenta funciones de tipo representativo (símbolo de la unidad y permanencia del Estado; árbitro y moderador de las instituciones; alto representante en las relaciones internacionales, artículo 56 de la $\mathrm{CE}$ ) que lo mantienen alejado de las funciones legislativas y de gobierno y, en general, de las relaciones entre las Cortes y al gobierno, definidoras de la forma de gobierno. ${ }^{4}$ La relación

3 Larios Paterna, Ma. Jesús, La participación ciudadana en la elaboración de la ley, Madrid, Congreso de los Diputados, 2003; Vintró Castells, Joan, "Un punto de partida: el marco normativo de la iniciativa legislativa popular en España”, en Vintró, Joan y Bilbao, Juan M., Participación ciudadana y procedimiento legislativo: de la experiencia española a la iniciativa ciudadana europea, Madrid, CEPC, 2011, pp. 13 y ss.

4 Por eso, para el profesor Isidre Molas, la monarquía no forma parte de la forma de gobierno. En su opinión, define solamente el carácter de la Jefatura del Estado. En MOLAS, Isidre, Derecho Constitucional, $4^{\mathrm{a}}$ ed., Madrid, Tecnos, 2008, p. 119. 
de la Corona con las Cortes y con el gobierno se limita básicamente a la sanción - formal - de las leyes (artículo 90 de la CE) o la propuesta de candidato a presidente del gobierno y la firma — también formal— del Decreto de disolución de las Cortes (artículos 99 y 115 de la CE).

El sistema parlamentario español se inspiró sobre todo en la Ley Fundamental de Bonn y el constituyente tuvo presente también la experiencia constitucional italiana (como contra modelo). Tal sistema se inserta dentro de los denominados parlamentarismos racionalizados, por voluntad expresa del constituyente (manifestada en la moción de censura constructiva, artículo 113 de la $\mathrm{CE}$ ), acentuada por la práctica política ulterior, con la consolidación de partidos muy estables y rígidos, con gran obediencia a las directrices de la dirección del partido por parte de sus grupos parlamentarios y de los diputados y senadores.

Además, se trata de un parlamentarismo bicameral imperfecto, con claro predominio del Congreso de los Diputados sobre el Senado. De este modo, las relaciones entre el Parlamento y el gobierno tienen lugar a través del Congreso y del presidente del gobierno. Es el Congreso el que inviste al presidente del gobierno (artículo 99 de la CE) y es el Congreso el que puede exigir responsabilidad a este, y lo puede hacer caer (moción de censura y cuestión de confianza, artículos 113 y 112 de la CE respectivamente). El Senado se mantiene al margen completamente de estos actos. Sus funciones se concentran en el control ordinario del gobierno, el indirizzo u orientación política, y el nombramiento de altos cargos institucionales (en los tres casos en condiciones formales de igualdad con el Congreso). Respecto a las funciones legislativa y presupuestaria, es una cámara de segunda lectura, completamente subordinada al Congreso. ${ }^{5} \mathrm{El}$ hecho que, desde 2004 hasta finales del 2011, el Partido Popular (en la oposición) haya tenido mayoría (relativa) en el Senado no ha dificultado en nada al gobierno socialista de Rodríguez Zapatero a sacar adelante su programa de gobierno. Por último,

5 El Senado se define constitucionalmente como cámara de representación territorial aunque sus funciones en este ámbito sean testimoniales. De hecho, los partidos nacionalistas están presentes en ambas Cámaras, pero es al paso por el Congreso cuando tienen lugar las negociaciones entre el gobierno y estos para sacar adelante los presupuestos o los proyectos legislativos. Nos hemos ocupado de ello en Castellà Andreu, Josep Ma., "El debate sobre la reforma del Senado y su incidencia en la forma de Estado y la forma de gobierno", en Albertí, Enoch y Carrillo, Marc (coords.), Estudios sobre la Constitución Española. Homenaje al profesor Jordi Solé Tura, 1er vol., Madrid, CEPC, 2008, pp. 419 y ss. 
el presidente del gobierno tiene la potestad de disolver una o las dos cámaras, prácticamente sin límites (artículo 115 de la CE), sin necesidad de agotar los cuatro años que dura la Legislatura. ${ }^{6}$

El sistema parlamentario, cuyos rasgos normativos principales se han enunciado, se ha de poner en relación, por un lado, con el régimen constitucional de los partidos políticos (los cuales "concurren a la formación y manifestación de la voluntad popular y son instrumento fundamental para la participación política", según el artículo 6 de la CE), que deja una amplia libertad de creación de los mismos, configurándose un modelo de democracia abierta, sin límites por razón de la ideología del partido. Aunque la legislación que regula los partidos ha cambiado en 2002 (la LO 6/2002 deroga la ley 54/1978) y ha introducido límites a las actividades de los partidos, que pueden disolverse judicialmente por llevar a cabo actos contrarios al principio democrático y a los derechos humanos (artículo 9), de ello no cabe deducir que se haya introducido un sistema de democracia militante, a la alemana, que el Tribunal Constitucional ha considerado que no se ajustaría al ordenamiento constitucional (STC 347/2003). Este cambio legislativo ha permitido la ilegalización del brazo político de la organización terrorista ETA, Batasuna (en una de sus diversas denominaciones). Esta situación ha cambiado a partir de las elecciones autonómicas del País Vasco de 2009 y ha seguido en las elecciones municipales, las forales de Navarra y las generales, todas de 2011, con la autorización por el Tribunal Constitucional de candidaturas relacionadas con la denominada "izquierda abertzale".

Por otro lado, y en lo que ahora interesa resaltar, el sistema parlamentario se ha de relacionar con el sistema electoral. En efecto, el sistema electoral para la elección del Congreso de los Diputados (igual ocurre con el del Senado) se ha mantenido estable desde 1977, al inicio de la Transición política a la democracia. La ley para la reforma política (Ley 1/1977) y el Decreto Ley que la desarrolla (DL 20/1977), regularon las primeras elecciones ge-

6 De hecho es lo que ha ocurrido en la mayor parte de legislaturas, desde el inicio del régimen constitucional, salvo en 2000 y 2004 (Aznar) y 2008 (R. Zapatero). A ello no ha influido el tener o no el gobierno una mayoría absoluta de apoyo en el Congreso, sino que, en unos casos, el presidente del gobierno ha disuelto el Parlamento en función de los intereses del partido del gobierno, y en otros (1982, 1996 y 2011) la convocatoria electoral anticipada se ha debido a la grave crisis política del momento, con la descomposición del partido del gobierno (Calvo Sotelo, UCD en 1982), los casos masivos de corrupción y terrorismo de estado (González, PSOE, 1996) o la gravísima crisis económica (R. Zapatero, PSOE, 2011). 
nerales de 15 de junio de 1977, pero al mismo tiempo sentaron las bases de la regulación electoral contenida en la Norma constitucional (artículos 68 y 69 de la CE) y posteriormente desarrollada por la Ley orgánica 5/1985, de régimen electoral general. Para el Congreso, se optó entonces, y luego se incluyó en la Constitución, un sistema proporcional con circunscripciones pequeñas (las 50 provincias además de las dos ciudades autónomas de Ceuta y Melilla). El Decreto Ley de 1977 añadía — y la LOREG mantuvo en 1985-: 1) un mínimo de 2 diputados por circunscripción y el resto a distribuir proporcionalmente en función de la población; 2) la fórmula D’Hondt como criterio de asignación de escaños, y 3) un mínimo del 3\% por provincia, que en la práctica sólo opera en las circunscripciones con gran número de escaños (artículos 162 y 163 de la LOREG). ${ }^{7}$ Además, en todas las elecciones salvo las del Senado (donde la lista es abierta, con un voto mayoritario corregido), los ciudadanos votan una candidatura, sin poder alterar el orden de la misma ni expresar ninguna preferencia (lista cerrada y bloqueada). La Ley de partidos (LO 6/2002) no exigen ningún mecanismo específico para la designación de los candidatos (como las primarias), por lo que el mandato constitucional de estructura y funcionamiento interno democráticos de los partidos (artículo 6 de la $\mathrm{CE}$ ) admite concreciones muy variadas, dejadas a la libre voluntad de cada partido.

La LOREG ha sido modificada en varias ocasiones, entre las que merece destacarse la de 2007 (LO 3/2007) por la que se incluye un criterio de composición equilibrada entre géneros en la formación de las candidaturas a todas las elecciones (40-60\%) (artículo 44 bis), ${ }^{8}$ y la de 2011 (LO 2/2011) que restringe el criterio de presentación de candidaturas a las Cortes, al obligar a los partidos y coaliciones sin representación parlamentaria a reunir un $0.1 \%$ de firmas en cada circunscripción para poder concurrir a las elec-

7 Las circunscripciones mayores son Madrid (36 diputados en la convocatoria de 20-11-2011), Barcelona (31) y Valencia (16). Las menores son las ciudades autónomas de Ceuta y Melilla con 1 diputado cada una, las provincia de Soria con 2, y con 3 un total de 8 provincias (Ávila, Cuenca, Guadalajara, Huesca, Palencia, Segovia, Teruel, Zamora). Otras 9 provincias eligen 4; 7 eligen 5 diputados; 8 eligen 6 diputados; 4 eligen 7 diputados; 6 eligen 8 diputados; 2 eligen 10 diputados, y 2 eligen 12 diputados. Como se ve, en 20 circunscripciones sobre 52 se eligen menos de 5 diputados con lo que la proporcionalidad apenas produce efectos de facto.

8 El TC lo consideró ajustado a la Constitución en la sentencia 12/2008. Esta reforma tuvo lugar sin el consenso el PP, que interpuso un recurso de inconstitucionalidad. 
ciones (artículo 169.3). ${ }^{9}$ Esta última reforma supone una vuelta de tuerca más en la limitación de candidaturas que pueden concurrir a las elecciones generales, lo que restringe el pluralismo político. ${ }^{10}$

El Tribunal Constitucional no se ha mostrado nada beligerante con respecto al modelo de democracia y al régimen electoral, avalando la legitimidad del sistema vigente, cada vez que le ha llegado un recurso. ${ }^{11}$ Aunque el Tribunal no se haya pronunciado expresamente sobre los efectos no proporcionales del régimen electoral en las elecciones al Congreso, sí ha tenido varias ocasiones para hacerlo en el contexto de impugnaciones de la barrera mínima de votos requerida para acceder al Parlamento, presentes en las legislaciones electorales autonómicas, y que ha justificado en nombre de la estabilidad gubernamental (desde la STC 75/1985). En otras, ha justificado la investidura del candidato del grupo parlamentario mayor en lugar de la disolución automática por falta de mayoría de gobierno en el Parlamento, en aras de garantizar el parlamentarismo racionalizado (así ya en la STC 16/1984). Por último, en no pocas ocasiones, últimamente con motivo de un recurso contra una ley de consultas populares en el País Vasco (STC 103/2008), ha confirmado el modelo existente de democracia (sólo) representativa en detrimento del espacio reconocido a las instituciones de democracia directa y semidirecta. ${ }^{12}$

En efecto, en la STC 119/1995, FJ 3, el Tribunal afirma el carácter excepcional de la democracia directa: la participación "normalmente se ejerce a través de representantes y [que] excepcionalmente, puede ser directamente ejercida por el pueblo" (cursiva añadida). El carácter "especial" o "extraordinario" del referéndum, "por oposición al ordinario o común de la repre-

9 Este criterio se ha aplicado por vez primera en las elecciones generales del 20 de noviembre de 2011 y ha supuesto una merma sustancial del número de candidaturas: un $50 \%$. Véasehttp://politica.elpais.com/politica/2011/10/25/actualidad/1319533759_195487. html.

10 Como "supuesto de perpetuación del sistema de partidos vigente" lo califica Enrique Álvarez Conde en "Presentación y estudio preliminar", en Álvarez Conde, Enrique y López de los Mozos, Alicia (dirs.), Estudios sobre la Reforma de la Ley Orgánica de Régimen Electoral General: la reforma continua y discontinua, Madrid, IDP, 2011, p. 30.

11 Sobre el tema, véase Expósito, Enriqueta y Martín, Esther, “", en Lupo, Nicola et al. (a cura di), La 'manutenzione' della giustizia costituzionale. Il giudizio sulle leggi in Italia, Spagna e Francia, Turín, Giappicchelli, 2012.

12 Véase Corcuera Atienza, Javier, "Los límites del "derecho a decidir", $R E D C$, núm. 86, 2009, p. 303 ss., y Tajadura, Javier, "Referéndum en el País Vasco”, Teoría y Realidad Constitucional, núm. 23, 2009, pp. 363 y ss. 
sentación política" (STC 103/2008, FJ 2), se pone en relación con la opción constitucional por la Monarquía parlamentaria como forma de gobierno: "acorde con esta premisa, diseña un sistema de participación política de los ciudadanos en el que priman los mecanismos de democracia representativa sobre los de participación directa" (STC 76/1994, FJ 3). El Tribunal, en esta última sentencia, aborda los límites de la iniciativa legislativa popular. El alto tribunal, en la STC 103/2008, FJ 2, a modo de recapitulación de su propia doctrina, concluye "En nuestro sistema de democracia representativa, en el que la voluntad soberana tiene su lugar natural y ordinario de expresión en las Cortes Generales (artículo 66.1 de la CE) y las voluntades autonómicas en los respectivos parlamentos de las comunidades autónomas, los mecanismos de participación directa en los asuntos públicos quedan restringidos a aquellos supuestos en los la Constitución expresamente los impone (caso de la reforma constitucional por la vía del artículo 168 de la CE y de los procedimientos de elaboración y reforma estatutarios previstos en los artículos 151.1 y 2 y 152.2 de la CE) o a aquellos que, también expresamente contemplados, supedita a la pertinente autorización del representante del pueblo soberano (Cortes Generales) o de una de sus Cámaras". Y remata su argumentación, afirmando la opción por la democracia representativa, de forma clara y un tanto grandilocuente:

Nuestra Constitución garantiza, de esa manera, a través de los procedimientos previstos en ella, en los Estatutos de Autonomía y en las demás leyes, uno de los sistemas democráticos más plenos que cabe encontrar en el derecho constitucional comparado. Se trata de una democracia representativa como regla general, complementada con determinados instrumentos de democracia directa, que han de operar, como es lógico y constitucionalmente exigido, no como minusvaloración o sustitución sino como reforzamiento de esa democracia representativa (cursiva añadida).

Un caso más reciente en que el Tribunal ha aplicado este criterio restrictivo, dando un paso más en la limitación a estas figuras participativas, es el ofrecido por la STC 31/2010, FJ 69, sobre el Estatuto catalán, en que excluye la posibilidad que las CCAA puedan convocar consultas populares por la vía de referéndum dado que la competencia estatal de "autorización" de dichas consultas (artículo 149.1.32 de la CE) cubre toda la institución referendaria, y no sólo su autorización. De este modo, el Tribunal justifica en el modelo constitucional de democracia representativa una interpreta- 
ción restrictiva de los cauces de democracia directa constitucionalmente establecidos ya de por sí previstos en términos restringidos.

El Tribunal es especialmente sensible a la garantía de la estabilidad de los gobiernos, lo que le lleva a, por un lado, justificar límites al acceso al Parlamento de candidaturas con escaso número de votos. Según dijo el Tribunal en la STC 75/1985, FJ 5, la finalidad de las barreras electorales es la de procurar que "la proporcionalidad electoral sea compatible con el resultado de que la representación de los electores en tales Cámaras no sea en exceso fragmentaria, quedando encomendada a formaciones políticas de cierta relevancia". Para el Tribunal "el proceso electoral en su conjunto, no es sólo un canal para ejercer derechos individuales (personales o de grupo) reconocidos por el artículo 23 de la CE, sino que es también, a través de esta manifestación de derechos subjetivos, un medio para dotar de capacidad de expresión a las instituciones del Estado democrático y proporcionar centros de decisión política eficaces y aptos para imprimir una orientación general de la acción de aquél... La experiencia de algunos periodos de nuestra historia contemporánea y la de algunos otros regímenes parlamentarios enseñan, sin embargo, el riesgo que, en relación con tales objetivos institucionales, supone la atomización de la representación política, por lo que no es, por lo tanto, ilegítimo que el ordenamiento electoral intente conjugar el valor supremo que, según el artículo 1.1 de la CE, representa el pluralismo - y su expresión, en este caso, en el criterio de la proporcionalidad - con la pretensión de efectividad en la organización y actuación de los poderes públicos."

Si en el recurso de amparo resuelto en la STC 75/1985 se cuestionaba la legitimidad de la barrera mínima del 3\% exigida por la legislación electoral aplicable en las elecciones catalanas (y en las del Congreso), en recursos posteriores se objetó la barrera del 5\% establecida por algunas CCAA, pero el Tribunal también en dichos casos la consideró legítima en términos constitucionales (STC 193/1989, para el caso de Murcia), invocando en su apoyo la práctica en derecho comparado. Ha llegado incluso a admitir, excepcionalmente, límites superiores para Canarias ( $6 \%$ en el conjunto del archipiélago y 30\% para cada isla) (STC 225/1998). En esta última sentencia, el Tribunal señala que el objetivo de las barreras de exclusión en Canarias no es sólo "favorecer la estabilidad gubernamental", sino también, en el caso de la barrera del 30\% para cada isla, "asegurar la presencia de fuerzas políticas mayoritarias en la circunscripción, pero minoritarias en 
el conjunto de la Comunidad Autónoma". Ello es un correctivo de la primera barrera, con base en el mandato constitucional del artículo 152.1 de la CE de asegurar la representación de las "distintas zonas" del territorio. En realidad se pone pegas a la representación de las candidaturas isleñas y se favorecen las candidaturas suprainsulares.

Por otro, la estabilidad gubernamental sirve asimismo para legitimar un sistema de investidura que, en caso de ausencia de mayoría parlamentaria, permitía el nombramiento del líder del grupo parlamentario con más escaños, e impedir de este modo la disolución del Parlamento y la convocatoria electoral inmediata. Esta era, en efecto, la situación en Navarra que fue impugnada ante el alto tribunal (artículo 29.3 de la LORAFNA entonces vigente, ya no desde la reforma de 2001). En la STC 16/1984, FJ 6, el Tribunal justifica esta opción legislativa "el modelo que establece la normativa examinada...se configura como una variante del sistema parlamentario nacional, con la peculiaridad de que trata de reglamentar explícitamente su funcionamiento, en sus diversos aspectos - tanto en la elección del gobierno...como en lo referente a la cuestión de confianza...o de la moción de censura parlamentaria...-, en lugar de dejar tales extremos — como es el caso de otros regímenes parlamentarios de mayor tradición y antigüedad-a la costumbre o a convenciones de diverso origen". Y sitúa en este contexto al mecanismo residual de investidura que evita la disolución:

Dentro de esta peculiaridad, propia de lo que se ha llamado 'parlamentarismo racionalizado' se prevé igualmente la posibilidad de que de las diversas propuestas que se efectúen no resulte la investidura de candidato alguno, y en tal caso, la solución adoptada es, frente a la disolución de la Cámara que se prevé en casos similares en la CE..., la de la propuesta a S.M. el Rey del candidato que designe el partido político que cuente con el mayor número de escaños." Esta opción, según el Tribunal, se ha de insertar en "el orden de valores y principios a los que sirve" este modelo parlamentario. Para el Tribunal, además del principio democrático y la forma parlamentaria de gobierno, "nuestra Constitución se inspira en un principio de racionalización de esta forma que, entre otros objetivos, trata de impedir las crisis gubernamentales prolongadas.

La LORAFNA y otros estatutos sirven al mismo objetivo que el artículo 99 de la CE, aunque en lugar de arbitrar la disolución automática ante la imposibilidad de designar un presidente de gobierno en el plazo de 2 meses, opten por prever un procedimiento subsidiario. Ahora bien el Tribunal 
impone un límite a este procedimiento excepcional, con el fin de no desnaturalizar la forma parlamentaria de gobierno, a saber: sólo puede entrar en juego cuando se hayan agotado todas las posibilidades que la Ley ofrece, y por tanto no cabe sustituir la voluntad de la Asamblea por ninguna otra. De este modo, se impide que el presidente del Parlamento foral pueda designar como presidente de la Comunidad Foral a un candidato que no hubiese sido propuesto a la Asamblea previamente.

Así pues, la realidad de la forma de Estado y de gobierno, así como del régimen electoral y de partidos, se ha ido conformando a partir de los datos normativos de la Constitución y sus normas de desarrollo (en particular, la legislación electoral y de partidos y los reglamentos parlamentarios), de la jurisprudencia constitucional que ha avalado las grandes opciones legislativas, y de la concreta práctica política que se ha producido desde 1979 hasta ahora, durante diez legislaturas. La situación se puede caracterizar por:

1. Protagonismo absoluto de los partidos en el Estado democrático, ${ }^{13}$ los cuales designan, con un gran margen de autonomía, los candidatos y elaboran las listas electorales, sin que los ciudadanos puedan alterarlas (salvo en el Senado). ${ }^{14}$

2. Uso marginal a las instituciones de democracia directa y semidirecta, y en particular del referéndum consultivo. ${ }^{15}$

3. La existencia de mayorías de gobierno estables, con práctica de la alternancia política. El que se hayan dado hasta ahora en el Congreso tantas mayorías relativas como absolutas (5/5 legislaturas), no ha impedido la formación de gobierno entorno al par-

13 Una visión crítica en Rebollo, Luis, "Representación política y Parlamento", Treinta años de Constitución, Valencia, Tirant lo Blanch, 2010, pp. 991.

14 Hasta la STC 124/2011, el Tribunal partía del principio de inalterabilidad de la papeleta o de la lista electoral, considerando dicho voto como nulo si había cualquier irregularidad (tachadura, añadido, signo...). Este criterio se flexibiliza con la reforma de la LOREG de 2011 (artículo 96.2) y también en la sentencia citada. De este modo, si la enmienda introducida por el elector consiste en señalar un nombre o bien aparecen otras modificaciones que no parezcan intencionadas o voluntarias, en dichos casos no afecta a la expresión de su voluntad lector y el voto es válido.

15 Se han llevado a cabo sólo 2 referendos consultivos: 1986: permanencia en la OTAN y 2005: tratado constitucional europeo. Apenas un número insignificante de iniciativas legislativas populares han sido aprobadas por las Cortes a largo del régimen constitucional vigente. 
tido vencedor en las elecciones ni la ulterior estabilidad del gobierno, con el apoyo de partidos nacionalistas que no entran en el gobierno. ${ }^{16}$ Apenas se ha utilizado la moción de censura constructiva (2 ocasiones) y la cuestión de confianza (otras 2 ), sin que salieran adelante.

4. Primacía del presidente, el cual dirige y coordina la acción del gobierno. ${ }^{17}$ El presidente del gobierno ha sido siempre, a la vez, el líder del partido mayoritario. ${ }^{18}$ Así pues, nos hallamos ante una "democracia inmediata", con una identificación del líder del partido ante los electores: es el candidato del partido a la presidencia del gobierno y encabeza la candidatura de su partido por la circunscripción de Madrid.

5. Consolidación de un sistema bipartidista imperfecto, con la presencia de partidos de ámbito territorial además de los de ámbito general. Los partidos nacionalistas actúan como fuerzas "bisagra". Además, es muy difícil la supervivencia de los partidos menores de ámbito nacional (salvo Izquierda Unida). ${ }^{19}$ La máxima expresión de esta tendencia ha tenido lugar en la IX Legislatura (2008-2011), en la cual PSOE y PP reunían el 91 \% de los parla-

16 Gobiernos de minoría: 1979-82: UCD; 1993-1996: PSOE; 1996-2000: PP; 2004-8: PSOE y 2008-11: PSOE. Gobiernos de mayoría: 1982-1986: PSOE; 1986-1989: PSOE; 1989-1993: PSOE; 2000-4: PP; 2011- : PP.

17 Es habitual en la doctrina española resaltar la tendencia presidencialista en la actuación del gobierno que tiene base en lo dispuesto en la propia Constitución (artículo 98.2 de la CE). Así Pérez Francesch, Juan Luis, El gobierno, $3^{\mathrm{a}}$ ed, Madrid, Tecnos, 1998, pp. 61 y ss.; Fernández-Miranda, Alfonso, "Sobre la forma de gobierno. ¿Un exceso de racionalización?, Treinta años de Constitución, Valencia, Tirant lo Blanch, 2010, pp. 847 y ss. La práctica política ha confluido con esta apreciación jurídico-constitucional.

18 Salvo Leopoldo Cavo-Sotelo, elegido presidente del gobierno en febrero de 1981, tras la dimisión de Adolfo Suárez, hasta la derrota electoral de UCD en octubre de 1982.

19 Se ha ido produciendo una concentración de voto en dos grandes fuerzas de centroizquierda, el PSOE, y centro-derecha, el PP. La UCD, que lideró la transición a la democracia quedó diezmada en 1982 (de 166 a 12 diputados) y desapareció a continuación; PSP se integró en el PSOE igual que sectores del PCE. Una escisión de UCD encabezada por su ex líder, Adolfo Suárez, creó el CDS, pero prácticamente desapareció tras las elecciones de 1993. El PP fue el resultado de la integración de distintas fuerzas de la derecha y el centro (AP, partidos pequeños, y grupos que abandonaron UCD y el CDS). En la IX Legislatura: IU ha tenido 2 diputados y $1 \mathrm{UPyD}$, un partido nuevo de centro izquierda de tipo españolista. En la X Legislatura, en cambio, ha habido una mayor dispersión del voto: IU 11 diputados y UPyD 4 diputados. 
mentarios en el Congreso (321 de 350) y $83.7 \%$ de los votos. En cambio, el hundimiento del PSOE el 20 de noviembre de 2011 ha traído como consecuencia que en la X Legislatura se haya producido un aumento de los grupos en el Congreso en detrimento del número de parlamentarios de los dos grandes grupos (296 de 350 diputados lo que supone un $83 \%$ de escaños y un $73 \%$ de votos).

\section{Propuestas de reforma normativa}

Las propuestas de reforma constitucional que se han formulado hasta ahora se han centrado básicamente en cuestiones de organización territorial (particularmente la transformación del Senado en cámara de las CCAA), la sucesión a la Corona, y la integración europea. En cambio, las dos reformas aprobadas hasta la fecha, por el procedimiento simple del artículo 167 de la $\mathrm{CE}$, han estado relacionadas con efectos de la pertenencia a la Unión Europea: 1) el Tratado de Maastricht en 1992 y la creación de la ciudadanía europea conllevó la reforma de 1992 que ampliaba el derecho de sufragio pasivo a los residentes no nacionales (reforma del artículo 13.2 de la CE), y 2) más recientemente en septiembre de 2011, y como consecuencia de la grave crisis económica y las exigencias de las instituciones europeas, la introducción del principio de estabilidad presupuestaria así como de límites al déficit y a la deuda pública (reforma del artículo 135 de la CE).

Por el contrario, ni las reformas aprobadas ni las propuestas de reforma han afectado al Título I dedicado a los derechos fundamentales, ni tampoco a la forma de gobierno (salvo la incidencia que sobre la misma pudiera tener la reforma del Senado). Ello muestra una notable estabilidad y una aparente satisfacción generalizada por la forma de gobierno. En cambio, cada vez es mayor la insatisfacción con el sistema electoral y, como consecuencia de las protestas del movimiento 15-M o de los "indignados" en 2011, con el papel marginal de la democracia directa en el sistema constitucional. ${ }^{20}$

Respecto al sistema electoral, los partidos pequeños de ámbito nacional siempre se han mostrado en desacuerdo, por los efectos distorsionadores que produce en su representación y su incidencia en la igualdad de voto. ${ }^{21}$

20 Véase García Herrera, Miguel A. y Maestro, Gonzalo, “15 M y 19 J: la crisis de la política en la crisis económica”, Jueces para la Democracia, núm. 71, 2011, pp. 5 y ss.

21 Por ejemplo, si se toman en cuenta los resultados electorales de las elecciones de 2008: CiU obtuvo 779.425 votos, lo que supuso 10 escaños; el PNV 306.128, 6 escaños; 
Si atendemos a lo ocurrido en la IX legislatura (2008-2011), se creó una subcomisión en el seno de la Comisión constitucional del Congreso dedicada a la reforma de la $\mathrm{LOREG}^{22}$ y se presentaron algunas iniciativas parlamentarias en este sentido. ${ }^{23}$ En términos generales, tratan de conseguir un sistema más proporcional.

Estas propuestas no han salido adelante por la falta de apoyo de los partidos mayoritarios (nacionales y territoriales). Otras propuestas, dentro de la lógica del sistema vigente, han dado lugar a las últimas reformas de la LOREG de $2011 .{ }^{24}$ Además, cabe añadir que estas iniciativas están conde-

en cambio IU con 969.946 votos, sacó 2 escaños y UPyD con 306.079 votos, alcanzó 1 escaño. En las elecciones de 2011: CiU obtuvo 1.014.263 votos (16 diputados), IU 1.680.810 (11 diputados), UPyD 1.140.242 (4 diputados), PNV 323.517 votos (5 escaños).

22 Subcomisión sobre posibles modificaciones del Régimen electoral general. Se constituyó el 2 de febrero de 2008 y se disolvió el 30 de junio de 2010. Curiosamente no formó parte de dicha subcomisión la diputada más beligerante en este asunto, Rosa Díez de UPD. Ver nota siguiente.

23 Merece destacarse la proposición de ley presentada al inicio de la Legislatura por la diputada de Unión, Progreso y Democracia, Rosa Díez, integrada en el Grupo Mixto, y que fue rechazada. La proposición de ley propugnaba una ampliación del número de diputados de 350 a 400 (el máximo permitido por la Constitución, artículo 68) y la reducción del mínimo de diputados por provincia de 2 a 1 Ver BOCG, Congreso de los Diputados, IX Legislatura, Serie B, 25 de abril 2008, núm. 99-1.

http://www.congreso.es/portal/page/portal/Congreso/PopUpCGI? CMD $=V E R L S T \& B A S E=p u w 9 \& D O C S=1-1 \& D O C O R D E R=L I F O \& Q U E R Y=\% 28 C$ DB20080425009901.CODI.\%29\# (p.1) (consultado el 3 de noviembre de 2011).

Además, la misma diputada presentó una proposición no de ley pidiendo una mayor proporcionalidad e igualdad de voto, también rechazada. Véase BOCG, Congreso de los Diputados, Serie D, 9 de febrero 2010, núm. 333.

En lo que va de X Legislatura se ha presentado una proposición de reforma constitucional para reforzar la participación política y el pluralismo en el régimen electoral, por el Grupo La Izquierda Plural y el Grupo Mixto (31-1-2012):

http://www.congreso.es/portal/page/portal/Congreso/Congreso/Iniciativas/IniTipo?_piref73_1335527_73_1335526_1335526.next_page=/wc/detalleDocumento\&idIni ciativa $=122 \&$ numExpediente $=43 \&$ numDocumento $=0 \&$ paginaActualB $=$ null .

${ }^{24}$ Merecen resaltarse la LO 2/2011: sobre el voto de los españoles que residen en el extranjero, la reforma de los delitos electorales, de la publicidad e información en los medios de comunicación, nuevas normas sobre la campaña. Y la LO 3/2011, con el objetivo de continuar con la batalla contra formaciones políticas que apoyen al terrorismo e impedir que concurran a las elecciones. Además se crea una causa de incompotibilidad sobrevenida para que concejales o parlamentarios de formaciones políticas que apoyen el terrorismo y que sean ilegalizadas a largo del ejercicio de su mandato representativo: si dichos representantes no se distancian expresamente de dicha formación perderán su acta 
nadas al fracaso, al no existir en España mecanismos de iniciativa popular que pudieran forzar a las Cámaras a abordar el tema, o bien provocar un pronunciamiento popular al margen de la voluntad de las Cámaras. En efecto, la iniciativa legislativa popular está excluida para las leyes orgánicas - artículo 87.3 de la CE— - y no existe en España un referéndum de iniciativa popular o abrogativo de leyes, como en Italia.

El Consejo de Estado, máximo órgano consultivo del gobierno, a instancia del Consejo de Ministros, también ha intervenido en el debate jurídico sobre la reforma del régimen electoral, emitiendo un informe en $2009 .{ }^{25} \mathrm{El}$ informe se sitúa dentro de los márgenes de la Constitución vigente, sin entrar a considerar una posible reforma en este campo. De entre los distintos aspectos abordados por el Consejo de Estado, merece destacarse en este contexto la propuesta - para "perfeccionar [lo: el sistema democrático] para mejorar la calidad de nuestra democracia"- $-{ }^{26}$ de incrementar la igualdad de voto y ampliar la proporcionalidad del voto mediante la ampliación del número de diputados y reducción a un escaño el mínimo por provincia. Otra tímida sugerencia afecta al desbloqueo de candidaturas con voto preferencial que "probablemente tendría efectos beneficiosos en la medida en la que sirve para fomentar la participación política de los ciudadanos y una mayor implicación de éstos en el funcionamiento democrático de las

de represente electo. Un análisis de las mismas en Chueca, Ricardo y Gavara, Juan C., La reforma de la Ley Orgánica de Régimen electoral general, Madrid, CEPC, 2011.

25 Informe del Consejo de Estado sobre las propuestas de modificación del régimen electoral general, 24 de febrero de 2009. Véase http://www.consejo-estado.es/pdf/ REGIMEN-ELECTORAL.pdf (consultado el 3 de noviembre 2011). Como advierte Ángel Sánchez, la reforma de la LOREG llevada a cabo por la LO 2/2011 aborda aspectos, por lo general, técnicos y accesorios que no afectan a los problemas centrales tratados por el Consejo de Estado, en Sánchez Navarro, Ángel, "El Consejo de Estado y la reforma electoral", en Álvarez Conde, Enrique y López de los Mozos, Alicia (dirs.), Estudios sobre la Reforma de la Ley Orgánica de Régimen Electoral General: la reforma continua y discontinua, cit., p. 109. En la misma obra, David Ortega advierte del hecho que la reforma de la LOREG hacen caso omiso de las propuestas del Consejo de Estado, en Ortega, David, "El informe del Consejo de Estado de 24 de febrero de 2009, sobre las propuestas de modificación del régimen electoral general. La apertura de nuestra democracia”, pp. 125 y ss. Véase, igualmente, Guillén, Enrique, "El sistema electoral del Congreso de los Diputados. Principios constitucionales y recientes propuestas de reforma. (Lo que nunca pudo haber sido y no fue)", Revista Española de Derecho Constitucional, núm 92, 2011, pp. 195 y ss., y Aranda, Elviro, "La reforma electoral: análisis y perspectivas", Asamblea: Revista Parlamentaria de la Asamblea de Madrid, núm. 24, 2011, p. 91 ss.

26 Ibidem, p. 358. 
instituciones", no sin advertir que dicha reforma "puede generar en el seno de aquéllos [los partidos] tensiones que dificulten la unidad de acción". El Consejo de Estado, en cambio, desaconseja las listas abiertas con un argumento de facto ("el ciudadano no hace uso de esa posibilidad...en las elecciones al Senado") y alerta sobre su peligro para la formación del gobierno ("puede generar alguna complejidad añadida"). ${ }^{27}$

Relevancia del plano autonómico: laboratorio para la experimentación en régimen electoral y forma de gobierno

\section{Situación anterior a las reformas estatutarias}

Como se ha indicado en el apartado anterior, los pronunciamientos del alto tribunal sobre la forma de gobierno y el sistema electoral han tenido su origen en recursos contra normas autonómicas. Su relevancia no obstante trasciende dicho plano, como se ha visto, dada la sustancial homogeneidad entre la forma de gobierno y el sistema electoral de las CCAA y sus equivalentes estatales. Las conclusiones del Tribunal son válidas, además, para todas las CCAA por otro factor: la relativa homogeneidad de regulaciones entre CCAA. Analicemos ambas características. ${ }^{28}$

Cuando los estatutos de autonomía tuvieron que diseñar las instituciones de gobierno de cada Comunidad Autónoma y las relaciones entre ellas siguieron de cerca, desde el inicio, el modelo de democracia representativa y parlamentaria racionalizada que la Constitución había previsto para el Estado central. También este modelo se expande a nivel municipal. ${ }^{29}$ De

27 Ibidem, p. 363.

28 El principio de homogeneidad institucional entre el plano nacional y el territorial, y entre los distintos entes subnacionales es habitual en derecho comparado. Tómese como ejemplo la forma republicana de gobierno que la Constitución americana exige a las constituciones de los estados (artículo 4.4) y su paralelismo con la forma republicana de la Constitución federal. O el sistema parlamentario canadiense previsto en la Ley constitucional de 1867 tanto para la Federación como para las provincias (y protegido con el procedimiento más agravado de reforma constitucional del artículo 41 de la Ley Constitucional de 1982 que requiere el consenso de todas las provincias). Incluso en el caso italiano, la Corte Constitucional ha interpretado en clave restrictiva el artículo 122 de la Constitución reformado en 1999 (Ley constitucional núm. 1 de 1999, la cual incluye como artículo 5 una Disposición Transitoria sobre el tema), que en principio dejaba un amplio margen a las regiones ordinarias para establecer su forma de gobierno.

29 Artículo 140 de la CE, Título III de la LOREG y Ley reguladora de las Bases del Régimen Local. De acuerdo con la LRBRL cada ayuntamiento tiene un Pleno, un alcalde 
entrada, el artículo 152.1 de la CE sólo exige el sistema parlamentario y un sistema electoral proporcional para las CCAA de régimen especial (las que hubiesen aprobado su Estatuto siguiendo el procedimiento del artículo 151.2 de la CE y la Disposición Transitoria II, esto es: País Vasco, Cataluña, Galicia y Andalucía).

Sin embargo, todos los demás estatutos adoptaron la misma forma de gobierno e instituyeron sistemas parlamentarios parecidos a los anteriores, más en concreto, al "modelo catalán". Ello pudo ser así a partir de la habilitación que efectúan dos preceptos constitucionales, los cuales no precisan la concreta forma de gobierno: el artículo 147.2.c de la CE establece que el Estatuto es la norma adecuada para regular "la denominación, organización y sede de las instituciones autónomas propias", ${ }^{30} \mathrm{y}$ el artículo 148.1.1 de la CE indica que, entre las competencias que pueden asumir las CCAA de vía ordinaria, figura, en primer lugar, la "organización de sus instituciones de autogobierno". Fueron los primeros pactos autonómicos entre el gobierno de la UCD y el PSOE — entonces en la oposición — de 1981, que tomaron como base el Informe de los expertos dirigido por el profesor García de Enterría, los que generalizaron el modelo previsto en el artículo 152.1 de la $\mathrm{CE}$ a todas las CCAA que se constituyeran. Este pacto político se trasladó a los estatutos de las 13 CCAA restantes, que fueron aprobados entre $1981 \mathrm{y}$ 1983. ${ }^{31}$ Es más, en los primeros estatutos —el vasco, el catalán y el gallego - no aparece ni la moción de censura ni la cuestión de confianza como tampoco la potestad de disolución anticipada del presidente, sino que se

y una Junta de Gobierno. La reforma de dicha ley llevada a cabo por la Ley 57/2003 acentúa los rasgos parlamentarios del sistema: un poder ejecutivo fuerte integrado por el Alcalde y la Junta de Gobierno, y un órgano con facultades normativas y de control: el Pleno que elige al alcalde y puede retirarle la confianza. En cuanto a la elección de los concejales, se aplica la regla D'Hondt, con barrera mínima del 5\%, y listas cerradas y bloqueadas (artículos 179 y 180 LOREG).

${ }^{30}$ La STC 247/2007 y, siguiéndola en este punto la STC 31/2010, considera la organización institucional como un contenido legítimo de tipo necesario del Estatuto.

31 Hasta las reformas estatutarias de los años noventa, existieron diferencias menores entre las CCAA especiales y las ordinarias en el plano institucional, como la limitación de los periodos de sesiones parlamentarias (4 meses en dos periodos al año), y el cobro de dietas por asistencia al Pleno y comisiones, y no de salario por los diputados. Estaba limitado el número de consejeros o miembros del Consejo de Gobierno. No se contemplaba la disolución anticipada por el presidente (salvo si en dos meses no se había investido al presidente). Tampoco se suelen prever instituciones como el Defensor del Pueblo o el Consejo Consultivo. Ver, por ejemplo, el Estatuto de Asturias de 1981, el primero en adoptar este tipo de reglas (artículos 26, 27, 32 y 33). 
limitan a establecer el principio de responsabilidad política del presidente ante el Parlamento (así artículo 36.4 del Estatuto catalán de 1979). Fueron leyes aprobadas por el Parlamento - además de los propios reglamentos parlamentarios - las que las previeron con posterioridad, siguiendo de cerca lo dispuesto en la Constitución para el Estado central. A partir del Estatuto andaluz, todos los estatutos aprobados más tarde (de las CCAA de vía ordinaria ya introdujeron dichos mecanismos de control). Solo las ciudades autónomas de Ceuta y Melilla, en los estatutos aprobados por las Cortes en 1995 siguieron un modelo institucional distinto, más parecido en este punto al local. ${ }^{32}$

Respecto al sistema electoral que regula las elecciones autonómicas, la Constitución (artículo 152.1) se limita a indicar, también de forma expresa para las CCAA de vía especial aunque igualmente se generalizó a todas las $\mathrm{CCAA},{ }^{33}$ que el sistema electoral que rige la elección de la Asamblea Legislativa (unicameral) debe ser proporcional. Se añade, a continuación, que debe asegurar, además, "la representación de de las diversas zonas del territorio". Los estatutos suelen concretar algunos aspectos, singularmente la circunscripción, que normalmente es la provincia, aunque en las CCAA formadas por archipiélagos sea la isla (Canarias e Islas Baleares), u otras circunscripciones menores en las comunidades uniprovinciales de Asturias y Murcia. Los estatutos dejan a la regulación

32 Ya que los presidentes de ambas ciudades autónomas son al mismo tiempo presidente del Ejecutivo y de la Asamblea representativa (aunque no legislativa) de la entidad. Véanse los artículos 14 y 15 de ambos estatutos de 1995. Nos hemos ocupado del tema en Castellà, Josep Ma. y Pons, Eva, "Los estatutos de autonomía de Ceuta y Melilla", Informe Pi i Sunyer sobre Comunidades Autónomas 1995-1996, Barcelona, Fundació Pi i Sunyer, 1997.

33 El Tribunal Constitucional no atendió el argumento del Abogado del Estado sobre la diferencia entre CCAA de régimen especial y ordinario en lo referente al sistema electoral proporcional, con base a que el mandato del artículo 152 de la CE se refiere expresamente a las primeras y no a las demás, sino que lo ha aplicado también a las ordinarias, como ocurre en el caso de Canarias (STC 225/1998, FJ 6). En cambio el Voto Particular concurrente de P. Cruz Villalón en dicha sentencia considera que el artículo 152.1 de la CE sólo se aplica a las CCAA que aprobaron su Estatuto por la vía del artículo 151 de la CE, no a las restantes, por lo que Canarias no está obligada a adoptar un sistema de representación proporcional, como el estipulado por dicho precepto. También en la STC 31/2010, sobre el Estatuto catalán, el Tribunal Constitucional equipara el tratamiento de la autorización del referéndum que pone fin al procedimiento de reforma del Estatuto a todas las CCAA, al margen de que estuviera previsto constitucionalmente sólo para las especiales. 
de la ley electoral propia otros aspectos tangenciales. En cualquier caso, la materia electoral está reservada en sus partes básicas a la LOREG, por lo que corresponde a las Cortes su aprobación. Las leyes de las CCAA han añadido algunos requisitos relevantes. ${ }^{34}$

Así, algunas CCAA han elevado la barrera mínima para obtener representación del 3\% (prevista en la LOREG para el Congreso) al 5\% (incluso no por circunscripción sino exigible para el conjunto de la Comunidad como en Galicia, Valencia y Murcia) o incluso al 6\% (Canarias), lo cual ha sido convalidado por el Tribunal Constitucional (STC 225/1998), como se ha visto.

A pesar de la coincidencia en sus líneas maestras con la forma de gobierno nacional, ya desde el inicio del régimen autonómico existen peculiaridades institucionales en las CCAA, que no se dan en el estatal.

Así, se mantienen y hasta se acentúan los rasgos típicos del sistema parlamentario, al exigir que el candidato a presidente de la Comunidad Autónoma sea diputado (artículo 152.1 de la CE y los Estatutos), a diferencia del presidente del gobierno, en cuyo caso la Constitución no lo exige. También se acentúa la racionalización del sistema. Una muestra de ello, que hoy ya solo está vigente en Castilla-La Mancha, es precisamente el procedimiento residual investidura del presidente, por el que, en caso de no obtener ningún candidato mayoría absoluta (en la primera votación) o simple (en segunda votación) y reiterarse durante dos meses otras votaciones con el mismo o distinto candidato, en lugar de seguir el modelo constitucional instituido para el gobierno del Estado (y asumido por la mayoría de las 17 CCAA) de disolver el Parlamento y convocar nuevas elecciones, ${ }^{35}$ se nombra presidente de la Comunidad Autónoma al candidato del partido con más escaños en la Asamblea (Castilla-La Mancha: artículo 14.5). ${ }^{36}$

34 Véase Gavara de Cara, Juan Carlos, La homogeneidad de los sistemas electorales autonómicos, Madrid, CEPC, 2007, y Oliver Araujo, Joan, Los sistemas electorales autonómicos, Barcelona, IEA, 2011.

35 Lo cual sólo ha ocurrido una vez: en la Comunidad de Madrid en 2003.

36 Esta era también la situación, antes de las reformas estatutarias, en Andalucía: artículo 37.3 y Navarra: artículo 29.3. Como se ha dicho, el Tribunal Constitucional consideró adecuado a la Constitución este procedimiento para el caso de Navarra en la STC 16/1984. Posteriormente tanto Navarra (reforma de 2001), como Andalucía (2007), en sendas reformas estatutarias, han abandonado este criterio y se han sumado al seguido por la mayoría de CCAA. 
Más en general, prácticamente todas las CCAA han ido atribuyendo al presidente la potestad de disolución anticipada de la Asamblea (salvo Canarias). Respecto al momento de la finalización de la nueva legislatura, se ha dado una diferencia entre las CCAA de régimen especial y las de régimen ordinario. En el primer supuesto, la nueva Legislatura podía durar hasta los 4 años de duración, propios de las legislaturas en España. Por el contrario, en el segundo caso, el nuevo Parlamento tenía una duración más limitada pues no se podía alterar la fecha de las elecciones: cada 4 años para las 13 CCAA de vía lenta o régimen ordinario. De este modo, la siguiente legislatura podía durar el tiempo que faltaba para llegar la anterior a los 4 años. Esta situación ha cambiado con los nuevos estatutos, los cuales han generalizado la extensión de la nueva legislatura a 4 años.

A partir de este cuadro normativo en materia electoral e institucional (y de la ausencia de normativa propia de las CCAA sobre partidos políticos), ${ }^{37}$ la realidad política ha dado lugar a prácticas heterogéneas, que han ido ampliando las diferencias con el modelo estatal y entre las CCAA entre sí. Así, de entrada, se ha ido conformado en las CCAA un subsistema de partidos distintos del estatal, más plural, con la presencia de partidos menores que no obtienen representación en el Congreso o el Senado. Ello se debe a que la misma fórmula D'Hondt aplicada en circunscripciones con un número mayor de parlamentarios produce un efecto más proporcional, sólo en parte compensado con una superior barrera mínima de acceso del partido a la Asamblea (5\% ordinariamente). Así pues, la diferencia con las elecciones generales no estriba en la circunscripción (que normalmente sigue siendo la provincia) sino en el número de escaños que cada una de ellas tiene asignado. ${ }^{38}$ Además, en las

37 Si bien o se puede olvidar como el cambio de la legislación de partidos en 2002 ha tenido efectos en la composición del Parlamento Vasco y en el de Navarra, con la ilegalización de Batasuna y otras candidaturas "contaminadas" por su vinculación con ETA, lo que les ha impedido la presentación de candidaturas electorales. Como se ha indicado en el texto, esta situación ha cambiado desde 2009 desde las elecciones al Parlamento vasco, las elecciones al Parlamento foral de Navarra de 2011 y las generales de 2011, debido a una interpretación más flexible de la normativa y a un cierto cambio de presentación en público de las fuerzas de la izquierda nacionalista.

38 Esto tiene como efecto que haya subsistemas de partidos distintos en las Cortes y en las Asambleas de las CCAA, ya que partidos — normalmente regionalistas o nacionalistas - que no obtienen representación en el Congreso, sí la tienen en dichas Asambleas, como es del caso del Partido Regionalista de Cantabria, Partido Aragonés Regionalista, Partido Socialista de Mallorca. 
CCAA ha sido habitual la formación de gobiernos de coalición (lo que no ha sucedido hasta ahora en el gobierno del Estado), incluso dejando fuera al partido que había obtenido una mayoría relativa. ${ }^{39}$ Esto último ha propiciado una consideración más "mediata" de la democracia, que otorga un poder muy grande a los partidos que negocian estos acuerdos de gobierno. La ciudadanía suele castigar en las siguientes elecciones estas fórmulas.

\section{Incidencia de las reformas estatutarias}

Los estatutos reformados a partir de 2006 han aportado alguna novedad relevante en relación con la forma de gobierno y el sistema electoral. ${ }^{40}$ En general se puede destacar que ha aumentado la heterogeneidad de situaciones en estos temas con relación al Estado. Al mismo tiempo se aprecia que tienden a equipararse los estatutos de las distintas CCAA. Cuando, como se verá a continuación, el Estatuto catalán intentó ensayar un rumbo propio en el caso del Consejo de Garantías Estatutarias, el Tribunal Constitucional lo ha reconducido a la regla general. Vamos a centrar nuestra atención a continuación en aspectos que son novedosos, y que no han sido abordados en el apartado anterior.

Así, en primer lugar, y respecto al régimen electoral, los nuevos estatutos suelen exigir una mayoría cualificada para la aprobación de la ley electoral, que ha pasado a ser de dos tercios (Comunidad Valencia-

39 Como ha ocurrido ya en bastantes ocasiones. Normalmente es el PSOE la fuerza política con mayor capacidad de formar coaliciones de gobierno con partidos diversos. En la actual legislatura: en Canarias (2011: Coalición Canaria-PSOE), y en Andalucía (2012: PSOE-IU). En cambio, el gobierno socialista de Asturias tiene el apoyo externo de IU (2012). En la anterior Legislatura hubo gobiernos de coalición en Aragón, Cantabria, Cataluña, Galicia, Illes Balears. El caso del País Vasco merece un comentario a parte, pues en la actual Legislatura el PSOE (segunda fuerza) obtuvo el gobierno gracias al apoyo externo del PP (tercera fuerza), que se ha roto a inicios de 2012, siendo la primera fuerza el PNV. Por la falta de apoyo al gobierno socialista, las elecciones autonómicas presumiblemente tendrán lugar de forma anticipada.

40 Se han aprobado las siguientes reformas estatutarias totales: Comunidad Valenciana y Cataluña (2006), Illes Balears, Andalucía, Aragón y Castilla y León (2007) y Extremadura (2011). A parte hay que mencionar la reforma parcial de la Ley de Reintegración y Amejoramiento del Fuero de Navarra (LORAFNA) de 2010. 
na, Cataluña, Illes Balears). ${ }^{41}$ Este requisito de mayorías cualificadas se explica por el aumento de la desconfianza entre los partidos por el uso pro-mayoría que se pueda hacer de las reformas electorales (como se ha visto en Castilla-La Mancha). ${ }^{42}$ De ahí la necesidad de formalizar en el Estatuto el requisito de la mayoría amplia, hasta las reformas normalmente implícito. Se incluyen menciones también a la paridad de género, siguiendo lo indicado en la LOREG con carácter general y para todos los comicios electorales. ${ }^{43}$

En segundo lugar, los estatutos han incorporado referencias más exhaustivas a la democracia directa, semidirecta y participativa. Hasta la reforma, los estatutos se referían a la iniciativa legislativa popular $\mathrm{y}$, en algunos casos, a las consultas populares por la vía de referéndum (de ámbito sólo municipal o también autonómico). Ahora, además de ambas figuras; ${ }^{44}$ aparecen como derechos estatutarios — como parte del contenido del derecho de participación-, y entre las competencias de la Comunidad Autónoma, se regula de manera más amplia las consultas populares. Existe una notable diferencia entre estos últimos contenidos entre los

41 En Extremadura se exige 3/5, y en Andalucía, Aragón y Navarra mayoría absoluta. En cambio, el Estatuto de Castilla y León no dice nada al respecto. En el caso catalán, aún no se ha aprobado la ley electoral. De hecho, es la única CCAA que se rige aún por la Disposición transitoria 4 del Estatuto de 1979, mantenida vigente por el Estatuto de 2006 (Disposición transitoria 2). Dicha disposición remite a la legislación electoral general para la elección del Congreso y añade únicamente el número de escaños que debe elegir cada circunscripción: la provincia: Barcelona 85, Tarragona 18, Girona 17 y Lleida 15. En la legislatura anterior, el gobierno catalán constituyó una comisión de expertos que elaboró el informe Participació, representació, transparencia (2007). Hasta ahora no ha sido posible alcanzar el consenso parlamentario requerido.

42 En la Legislatura anterior (2007-11), Castilla-La Mancha aprobó una modificación de su ley electoral que cambia el número de escaños de dos circunscripciones (de 47 a 49). La ley pasó con el voto de la mayoría socialista pero el PP, único partido de la oposición, se opuso. El PP impugnó la ley ante el TC, el cual en la STC 19/2011 consideró que no vulneraba la Constitución. En la presente Legislatura, el nuevo gobierno del PP ha modificado otra vez la ley electoral en 2012 aumentando el número de diputados a 53.

43 Tampoco esta reforma del artículo 44 bis de la LOREG contó con los votos del principal partido de la oposición, el PP, el cual la impugnó ante el TC. Éste, sin embargo, en la STC 12/2008 consideró la reforma adecuada a la Constitución

${ }^{44}$ La ley de iniciativa popular catalana fue reformada (Ley 1/2006) permitiendo su ejercicio por ciudadanos mayores de 16 años (en lugar de 18), por residentes legales (no ciudadanos españoles) y dando posibilidad a los promotores de defenderla ante el Parlamento de Cataluña e incluso el derecho de retirada si, a lo largo del debate parlamentario, se aparta del texto inicial. 
estatutos reformados: algunos excluyen expresamente el referéndum de las consultas populares (Andalucía, artículo 78; Aragón, artículo 71.27; Extremadura, artículo 9.1.50), mientras que otros no lo mencionan pero tampoco lo excluyen (Cataluña, artículo 122; Comunidad Valenciana, artículo 28.5; Illes Balears, artículo 31.10; Castilla y León, artículo 71.1.15). El Tribunal Constitucional en las SSTC 103/2008 y 31/2010 ha marcado los límites de forma muy restrictiva a la posibilidad de que las CCAA organicen referendos. ${ }^{45}$ En cambio, deja la puerta abierta a que la legislación ordinaria autonómica prevea otras modalidades de consulta, encuadrables en la categoría "democracia participativa". ${ }^{46}$

La cuestión interesante está en saber si la introducción del referéndum altera de algún modo la forma de la Comunidad Autónoma y su forma de gobierno, que, como se ha visto, en el plano nacional y hasta ahora en el autonómico, es de claro predominio de la democracia representativa y de papel marginal (más que complementario) de la democracia directa.

45 Cataluña es la única que por ahora ha aprobado una ley sobre referendos: la Ley 4/2010, sobre consultas populares por vía de referéndum, sea para el ámbito autonómico que para el municipal. Nos hemos referido a la cuestión en Castellà, Josep Ma., "Las consultas populares en la sentencia 31/2010, sobre el Estatuto de Autonomía de Cataluña", en Álvarez Conde, Enrique y Rosado, Cecilia (dirs.), Estudios sobre la Sentencia 31/2010, de 28 de junio, del Tribunal Constitucional sobre el Estatuto de Autonomía de Cataluña, Madrid, IDP, 2011, p. 197 ss. Está pendiente de resolución el recurso de inconstitucionalidad presentado por el presidente del gobierno contra la Ley catalana 4/2010. En general sobre el referéndum autonómico, ver también Uriarte Torrealdai, Roberto, "Notas sobre la admisibilidad constitucional de las consultas populares de ámbito autonómico", Revista Vasca de Administración Pública, núm. 82 (I), 2008, p. 248 ss; López Basaguren, Alberto, "Sobre referéndum y Comunidades Autónomas. La ley vasca de la 'consulta' ante el Tribunal Constitucional”, Revista d'Estudis Autonòmics i Federals, núm. 9, 2009, pp. 202 y ss., y Aguado, César, "El referéndum autonómico", en Matia, Javier (dir.), Pluralidad de ciudadanías, nuevos derechos y participación democrática, Madrid, CEPC, 2011, p. 389 ss. El nuevo gobierno nacionalista catalán de CiU ha presentado al Parlamento de Cataluña en 2012 un proyecto de ley sobre consultas populares no referendarias que trata de evitar la necesidad de autorización por el gobierno del Estado de la consulta (149.1.32 de la CE). El problema estriba en que el instituto regulado por este proyecto de ley es sustancialmente un referéndum, con lo que es muy dudosa su constitucionalidad.

46 Hasta ahora la Comunidad Valenciana y Canarias han aprobado leyes de participación ciudadana, con contenidos muy vagos y generales: Ley valenciana 11/2008 y Ley canaria 5/2010. De tono y alcance bien distintos es la Ley foral Navarra 12/2012 sobre transparencia y gobierno abierto. Ver CASTEL, Sergio, "Descentralización política, participación ciudadana y renovación jurídica: ¿hacia una democracia participativa?, Revista Catalana de Dret Públic, núm. 43, 2011, pp. 279 y ss. 
Aunque de la literalidad de las normas estatutarias era posible otra interpretación más abierta al papel del referéndum, de acuerdo con la doctrina del Tribunal Constitucional, se opta por favorecer el desarrollo de las instituciones de democracia participativa (audiencias, foros...) al tiempo que se veda toda posibilidad a la democracia directa, con lo cual difícilmente se puede sostener que incida sobre la forma de la Comunidad y sobre la forma de gobierno.

En tercer lugar, el presidente de la Comunidad Autónoma es al mismo tiempo presidente de la Comunidad (funciones representativas) y presidente del Consejo de Gobierno (funciones de dirección política). No existe pues una bicefalia, o un primer ministro autonómico. Otra cosa es que algunas CCAA hayan previsto la figura del Consejero primero o del vicepresidente, que puede desempeñar algunas funciones de aquel, pero el que concita la confianza parlamentaria y el que responde ante el Parlamento es el presidente de la Comunidad Autónoma. El caso catalán puede ser interesante al respecto. En efecto, el Estatuto de 2006 prevé la figura del "consejero primero" (artículo 69). El artículo se limita a señalar que debe ser nombrado por Decreto del presidente, dando cuenta al Parlamento; que es miembro del gobierno, y que tiene funciones propias además de las delegadas por el presidente. En cualquier caso, la sustitución no alcanza al planteamiento de una cuestión de confianza, el nombramiento o cese de consejeros, así como la disolución anticipada del Parlamento (artículo 67.8). La Ley 13/2008, de la presidencia de la Generalitat y del Gobierno, ha concretado las funciones de esta figura y las ha distinguido de las del vicepresidente. Así, el consejero primero puede "desplegar las directrices generales de la acción de gobierno" (artículo 14.3.a), lo que no puede hacer el vicepresidente, artículo 15.3; además éste es titular de un departamento concreto; no así el consejero primero, artículo 15.2). Sorprende como, justamente tras la aprobación del Estatuto de 2006 que menciona sólo al consejero primero, la Ley de 2008 haya añadido un vicepresidente, con menores funciones que el primero. La explicación se halla en coyunturas políticas de aquel momento en Cataluña: la correlación de fuerzas y las relaciones entre los partidos de la coalición de gobierno ("tripartito" de izquierdas).

En cuarto lugar, algunas CCAA han incluido en los estatutos la posibilidad de limitar los mandatos del presidente (Cataluña, artículo 67.2 del EAC, con remisión a la ley). Ahora bien, sólo en Castilla-La Mancha, se 
ha legislado para concretar dicha limitación: así se había incluido en la reforma estatutaria (parcial) de 1997, que remitía a la ley del gobierno y del Consejo Consultivo (artículo 13.2), y se aprobó tal ley (Ley 11/2003), que establece en su artículo 4.2 "No podrá ser elegido presidente de la Junta de Comunidades quien ya hubiese ostentado este cargo durante al menos ocho años, salvo que hayan pasado cuatro años desde la terminación de su mandato". Se trata de la única normativa en este sentido que existe en España.

En quinto lugar, el sistema de las fuentes del derecho se ha visto igualmente alterado sobre todo con la previsión totalmente novedosa del decreto ley, en manos del gobierno, siguiendo de cerca los pasos que la Constitución atribuye a esta categoría normativa en el plano estatal. De este modo, se da al gobierno autonómico un importante poder normativo para legislar en situaciones de urgencia y necesidad, del que hasta ahora carecía. ${ }^{47}$ Otra cosa es que los reglamentos de los Parlamentos autonómicos hayan previsto, desde el primer momento, especialidades en el procedimiento legislativo que permitan acortar los tiempos de aprobación de una ley (particularmente leyes de lectura única, además del procedimiento de urgencia o leyes de comisión), lo cual sumado al hecho de que se trata de parlamentos unicamerales, permite poner en duda la necesidad de expandir el decreto ley al plano autonómico. Esta innovación en el terreno de las fuentes del derecho, se suma a la creación de leyes de desarrollo estatutario (cuya aprobación requiere de mayoría absoluta en votación final de conjunto) para materias de cierto relieve (carta de derechos, leyes institucionales, de organización territorial). En ausencia de leyes orgánicas en el plano autonómico (lo que no es sino una excepción a la forma de adoptar las decisiones por mayoría simple), y ante la situación anterior a las reformas estatutarias de previsión de esta categoría normativa generalmente en leyes ordinarias, que había sido criticada por la doctrina, ahora se han incorporado en los Estatutos, que es la norma sobre la producción de normas o norma normarum (como confirma la STC 31/2010).

Por último, el Estatuto catalán de 2006 había previsto un supuesto especial de intervención del Consejo de Garantías Estatutarias en el pro-

47 Una visión crítica en Herráiz Serrano, Olga, "Teoría y práctica del decreto-ley autonómico tras su incorporación al sistema de fuentes de algunas comunidades", Corts. Anuario de Derecho Parlamentario, núm. 25, 2011, pp. 105 y ss. 
cedimiento legislativo: a través de un dictamen vinculante del Consejo de Garantías para el caso de proyectos o proposiciones de ley que desarrollen o afecten a derechos estatutarios (artículo 76.4). De este modo, la intervención determinante de un órgano jurídico de garantía en medio del procedimiento legislativo, sin ser una segunda cámara, iba a tener una gran incidencia en la aprobación de una ley. La STC 31/2010 consideró inconstitucional este precepto alegando que si tiene lugar el pronunciamiento del órgano de garantía en medio del procedimiento legislativo como efectivamente ocurre de acuerdo con la ley de desarrollo - se vulneraría el derecho fundamental de participación en los asuntos públicos (artículo $23 \mathrm{CE}$ ), y si tuviera lugar al final del procedimiento legislativo se asemejaría a un tribunal constitucional, lo que atenta al monopolio que ostenta dicho órgano en el control de constitucionalidad de las leyes. ${ }^{48}$ Ahora todos los dictámenes de esta institución son pues consultivos. De este modo, el Tribunal ha reconducido hacia el modelo previo - y general- lo dispuesto en el Estatuto catalán de 2006: un Consejo que emite dictámenes consultivos, entre otros supuestos, sobre la adecuación a la Constitución y el Estatuto de los proyectos y proposiciones de ley que se discuten en el Parlamento autonómico, generalmente a instancias del gobierno autonómico y de las minorías parlamentarias. Esto también tiene otra consecuencia que ahora merece resaltarse: ha desaparecido la impronta que dicha institución hubiese tenido en la forma de gobierno de la Comunidad Autónoma, de haberse mantenido el dictamen vinculante.

Así pues, a la vista de los rasgos que se acaban de mencionar, se constata como las últimas reformas estatutarias han incorporado novedades que, de entrada, podían incidir en la forma de la Comunidad Autónoma, y en la forma de gobierno, a la vez que permitirían incrementar la asimetría entre las CCAA, pero que han sido desactivadas por el Tribunal Constitucional: son los casos potenciales del referéndum y el Consejo de Garan-

48 Véase Aparicio, Miguel A. y Barceló, Mercè (coords.), Los órganos garantes de la autonomía politica, Barcelona, Atelier, 2009. Sobre las reformas estatutarias en España en este punto, se puede consultar el monográfico dedicado a "los guardianes de la autonomía" de la Revista Catalana de Dret Públic, núm. 39, 2009, y Delgado, Luis, "El Consejo de Garantías Estatutarias: de órgano consultivo de la Generalitat a órgano de control jurídico y de tutela institucional de los derechos estatutarios”, en Matia, Javier (dir.), Pluralidad de ciudadanías, nuevos derechos y participación democrática, cit., p. 225 ss. Este último autor invoca como argumento favorable al pronunciamiento del TC, la afectación a la forma de gobierno parlamentaria autonómica (pp. 252 y 253). 
tías Estatutarias con capacidad de emitir dictámenes vinculantes (ambos en el caso del Estatuto catalán y su desarrollo legislativo). En cambio, lo que sí se ha confirmado en los nuevos estatutos es el reforzamiento del gobierno frente al Parlamento (atribución de la potestad de dictar decretos-leyes) y del presidente respecto al Parlamento, con la confirmación de la disolución anticipada a iniciativa del presidente $\mathrm{y}$, sobre todo, la extensión de la duración de la siguiente legislatura hasta 4 años. Esto último, además, provoca un efecto de ruptura de la homogeneidad en la fecha de celebración de las elecciones: frente a la celebración conjunta para los parlamentos autonómicos de las 13 CCAA de Estatuto ordinario (coincidiendo con las elecciones locales en todos los municipios españoles: el último domingo de mayo de cada 4 años) como hasta ahora ha venido ocurriendo desde las primeras elecciones de 1983, ahora cada Comunidad Autónoma podrá celebrar elecciones en fechas distintas. Por último, la limitación de mandatos del presidente, de generalizarse, introduciría un contrapeso eficaz a los mayores poderes que ostenta, pero sólo Castilla-La Mancha lo ha regulado hasta la fecha.

En definitiva, la forma de gobierno de las CCAA va hacia una tendencia "semipresidencialista", según detectara ya Solé Tura en 1985,49 que consiste en atribuir poderes amplios al Ejecutivo y, en particular, a su presidente. Ahora, de forma incipiente, - y esto sería lo novedosocomienza a pensarse en la limitación de los mandatos del presidente. En consecuencia, la lógica presidencialista no deja de incrementarse. Los gobiernos de coalición se han mostrado, por ahora, como el límite político más eficaz a esta tendencia.

\section{A MODO DE CONCLUSIÓN}

En los últimos tiempos, en España todo parece indicar que hay una profunda desafección política entre la ciudadanía y que se amplía la distancia entre gobernados y gobernantes. Los estudios demoscópicos si-

49 Solé Tura, Jordi, "Les Comunitats Autònomes com a sistemas semipresidencials", El govern a la Constitució espanyola $i$ als estatuts d'autonomia, Barcelona, Diputació de Barcelona, 1985, p. 280. Para dicho autor y ponente constitucional, no sería adecuado hablar de sistema parlamentario en las CCAA, y el predominio presidencial conlleva un aumento de las tendencias plebiscitarias (p. 293). Obviamente se usa en términos amplios, que no pueden equipararse a la V República francesa. 
túan cada vez más a los políticos, partidos y gobierno entre los problemas mayores: en concreto, están ya en tercer lugar (tras el paro y la crisis económica). ${ }^{50}$ Una primera respuesta popular en la calle tuvo lugar con la explosión del Movimiento "15-M" o de los "indignados", en Madrid y en otras ciudades españolas, en primavera de 2011. A pesar de la heterogeneidad de los participantes y de sus propuestas, la reivindicación de una "democracia más real" fue muy coreada. Desde esos sectores sociales, y otros políticos y académicos más o menos relacionados con los primeros, se lanzó entonces una campaña para proponer la celebración de un referéndum para la aprobación de la reforma del artículo 135 de la CE que consagra el principio de estabilidad presupuestaria (publicada el 27 de septiembre de 2011), que finalmente no se celebró al no alcanzarse las firmas de 1/10 de diputados o senadores que tienen la iniciativa (de acuerdo con lo requerido por el artículo 167 de la CE).

En el contexto de las propuestas sobre regeneración democrática (que son variadas y van más allá de las anteriores citadas), el debate sobre la reforma electoral —en un sentido más proporcional — volvió a hacerse presente durante la campaña electoral para las elecciones generales del 20 de noviembre de 2011, así como otras iniciativas tendentes a promover un acercamiento entre electores y elegidos, la potenciación de la democracia directa y participativa, o la transparencia y el control sobre la Administración. Como no solía ocurrir hasta ahora, las propuestas surgen de sectores intelectuales, económicos, sociales muy heterogéneos entre sí, de fuera del ámbito político, a los que ahora hay que añadir las provenientes de los propios grupos políticos mayoritarios. Ello es síntoma de lo generalizado del descontento y de la urgencia en la demanda de soluciones.

Habrá que ver si, a lo largo de la X Legislatura que empezó en diciembre de 2011, las iniciativas de regeneración democrática son tomadas en cuenta en las Cortes Generales - y en concreto por el Partido Popular, como grupo mayoritario en ambas cámaras - como una prioridad política. Hasta ahora los grandes partidos se han mostrado muy recelosos a la hora de reformar el sistema electoral e introducir otras reformas de contenido democrático, sea de tipo legislativo sea de modo de funcionamiento

50 Por ejemplo, el último barómetro del CIS del mes de julio 2012, http://estaticos. elmundo.es/documentos/2012/08/06/barometro_julio.pdf. 
de partidos e instituciones (democracia interna en los partidos, derechos en el ejercicio del cargo del parlamentario...). Hasta ahora el gobierno central ha promovido un ambicioso proyecto de ley de transparencia y buen gobierno, ${ }^{51}$ y el gobierno de Galicia impulsa la reducción sustancial del número de diputados autonómicos, medida que hay que situar en el contexto de la crítica social a los gastos de la política. ${ }^{52}$

El sistema político español se muestra cada vez más como un sistema bloqueado que impide que propuestas que salen de "fuera", esto es, de la sociedad civil y la academia, hallen eco y lleguen a debatirse en las instituciones parlamentarias. No ayuda al efecto que la Constitución no prevea el referéndum de iniciativa popular, ni tampoco que se rodee a la iniciativa legislativa popular de múltiples obstáculos para su ejercicio habitual. A través de este tipo de mecanismos de participación popular se permitiría un diálogo más abierto con la ciudadanía. Se suma a lo anterior la inexistencia de otros mecanismos efectivos de contrapeso interinstitucional y de control efectivo del gobierno (entre el Congreso y el Senado, o de las Cortes respecto al gobierno, o de instituciones como el Defensor del Pueblo o el Tribunal de Cuentas). Y lo mismo sucede en el plano autonómico, desaprovechando las ventajas de la cercanía entre gobernantes y gobernados en este ámbito de gobierno subnacional.

A lo largo de los más de treinta años de régimen democrático constitucional en España, la forma de gobierno parlamentario racionalizado, y el sistema electoral (sin olvidar tampoco el de partidos) se han caracterizado por su continuidad, rigidez así como por la estabilidad política que ha producido. Además, las CCAA han copiado esos sistemas institucional y electoral, aportando escasas novedades relevantes, a pesar de disponer de márgenes constitucionales para introducir variaciones adecuadas a su situación y voluntad concretas. Y cuando lo han intentado, el Tribunal Constitucional ha sido muy receloso a la hora de admitir variaciones al marco general. Habrá que ver si las posibilidades que introducen los nuevos estatutos de autonomía logran cambiar la dinámica política asentada hasta ahora, aunque lo dudemos, porque son los mismos actores políticos los encargados

51 http://www.leydetransparencia.gob.es/anteproyecto/index.htm (consultado agosto 2012). Falta ahora su tramitación en las Cortes. Algunas CCAA han aprobado recientemente leyes ambiciosas en esta línea, como ya se ha visto.

52 De los actuales 75 a 61 . Se han producido algunas críticas sobre los efectos de esta pretendida reforma: acentuación del peso del voto de las provincias rurales sobre las urbanas, lo que beneficiaria al PP. 
de hacerlo posible. Tal y como se ha visto a lo largo de estas páginas, en el sistema político español se ha consagrado el dominio exclusivo de los partidos -y más en concreto, de sus direcciones nacionales-, y en el sistema parlamentario la primacía absoluta del presidente del gobierno que es a la vez el líder del partido del gobierno - sobre la propia mayoría parlamentaria y, fácilmente, sobre el mismo Parlamento. Todo ello aleja a la ciudadanía del proceso de toma de decisiones políticas. Parece que ha llegado el momento de reorientar la dirección tomada hasta ahora.

Fecha de recepción: 16 de abril de 2012.

Fecha de dictamen: 10 de junio de 2012. 